Lutter/Bayer (Hrsg.) · Holding-Handbuch 



\title{
Holding- Handbuch
}

\author{
Konzernrecht \\ Konzernsteuerrecht \\ Konzernarbeitsrecht \\ Betriebswirtschaft
}

herausgegeben von

Prof. Dr. Dr. h.c. mult. Marcus Lutter

Prof. Dr. Walter Bayer

Bearbeiter siehe nächste Seite

5. neu bearbeitete und

enweiterte Auflage

2015

ottoschmidt 
